\title{
HASTA QUE LA MUERTE LOS SEPARA. LEGÍTIMA, DERECHO DE PROPIEDAD Y PROHIBICIÓN DE DISPOSICIÓN DEL TITULAR DE LOS BIENES: UN EJEMPLO PRÁCTICO DE INCONSISTENCIA NORMATIVA*
}

\author{
Alberto Carrio Sampedro \\ Universitat Pompeu Fabra \\ alberto.carrio@upf.edu
}

RESUMEN. La institución de la legítima ha generado un interesante debate entre la doctrina iusprivatista que atañe a dos cuestiones estrechamente emparentadas con la teoría del Derecho, como son la función y estructura del ordenamiento jurídico.

En el presente artículo examino cuáles y de qué tipo son las razones que se ofrecen a favor y en contra de la legítima. Esto me permite distinguir las razones justificativas de las identificativas del Derecho. Es decir, las que se refieren al porqué de la legítima de las que informan de qué es la legítima, o lo que es lo mismo, cuál es la configuración de este instituto en el ordenamiento jurídico. A continuación examino la compatibilidad de la legítima con los derechos de herencia y de propiedad tal como vienen enunciados en la Constitución española. Propondré entonces dos posibles interpretaciones del enunciado constitucional que vincula ambos derechos y mostraré qué argumentos sustentan una y otra.

Finalmente pongo de manifiesto la incoherencia de la legítima con una de las dos posibles interpretaciones del art. 33.1 de la Constitución española y la dudosa compatibilidad con la otra al situar en una posición de privilegio a ciertos parientes del causante, o si se prefiere, en una posición de no derecho al propietario de los bienes. Es decir al titular de un derecho que goza de garantía institucional.

El artículo concluye con un apéndice en el que i) identifico el tipo de inconsistencia que introduce la legítima en el ordenamiento jurídico español, y ii) propongo reconducir el debate a partir de una distinción adecuada entre el ámbito de justificación e identificación del Derecho.

Palabras clave: legítima, propiedad, herencia, coherencia del ordenamiento jurídico, inconsistencia, identificación y justificación del Derecho.

* Fecha de recepción: 20 de julio de 2016. Fecha de aceptación: 16 de febrero de 2017.

Agradezco a Sebastián AgüEro, José Luis Pérez TriviÑo, Lorena RAmíreZ y Josep Maria Vilajosana haberse tomado la molestia de leer las versiones previas de este artículo y la generosidad de sus comentarios y sugerencias que me han permitido mejorarlo formal y sustancialmente. Asimismo quiero agradecer a los revisores anónimos de Doxa sus acertadas observaciones y comentarios. 


\section{Until Death do Them Part. Legitimate Portion, Ownership and the Ban on the Disposal of Goods by the Property Holder: a Practical Example of Normative Inconsistency}

ABSTRACT. Forced heirship has raised an interesting disagreement among academics, which is linked with two key questions of Legal theory: the function and structure of Legal systems.

In this article I examine what are the pro and cons of forced heirship and what kind of reasons support each of them. This allows me to distinguish between justificatory and identifying reasons of the Law. This is, the reasons that answer the question of why should or should not exist forced hiership from the reasons that explain what forced heirship is. Next I examine the compatibility of forced heirship with both, the rights of inheritance and property as they are enounced by the Spanish Constitution. Then, I will propose two ways of interpretation of the constitutional text in which both rights are linked, and I will try to show what their grounds are.

Finally, I show the incoherence of forced hiership with one of the two possible interpretations of the Spanish Constitution, and the hard compatibility with the other one. Certainly, forced hiership puts into a position of privilege some relatives of the holder of the right of property while places the proper holder in a position of no right.

The article ends with an appendix in which I identify what kind of inconsistency introduces force hiership in the Spanish legal system and a way to bring fruitful the academic debate from the proper distinction between the justificatory and identifying domains of the Law.

Keywords: forced hiership, property, inheritance, coherence of Legal system, inconsistency, identifying and justification of the Law.

\section{INTRODUCCIÓN}

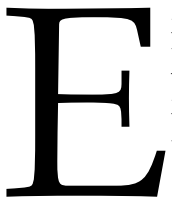

n el presente artículo me propongo examinar la institución jurídica de la legítima tal y como se encuentra actualmente configurada en nuestro ordenamiento jurídico. Dos son las razones que me mueven a ello. De una parte, participar modestamente en el debate generado entre la doctrina más autorizada en relación con este instituto jurídico. En este sentido, analizaré las razones que se ofrecen a favor y en contra del mismo, que son, como veremos en el apartado segundo, razones justificativas de su permanencia, modificación o derogación. La segunda razón, aunque emparentada con lo anterior, tiene que ver con una cuestión menos coyuntural. La de comprobar el encaje constitucional de la legítima y, en suma, la coherencia interna del ordenamiento jurídico, que analizaré en el apartado tercero. En el cuarto apartado examino la relación entre los derechos de propiedad y de herencia que establece el art. 33.1 de la Constitución española. Sostendré que el tenor literal de este artículo permite dos lecturas contrapuestas y enunciaré dos tesis interpretativas que se desprenden de cada una de estas lecturas del texto constitucional. Denominaré tesis de la conjunción de la titularidad (TCT) a la primera y tesis de la disyunción de la titularidad (TDT) a la segunda. En el siguiente apartado, el quinto, examinaré las razones que avalan cada una de estas tesis y la relación que guarda con ellas el instituto de la legítima. Mostraré entonces que la legítima tan solo es compatible con la segunda de estas tesis si se prueba que la garantía institucional de la herencia se extiende también al derecho de los legitimarios. Con la intención de enfocar adecuadamente el debate y comprobar cuáles son las vías de solución del aparente dilema al que conduce, el artículo concluye con un apéndice en el que identifico el tipo de inconsistencia que genera la legítima en el ordenamiento jurídico. Con todo ello trato 
de poner de manifiesto que el debate, para ser fructífero, debe deslindar claramente los argumentos que se ofrecen en el ámbito de identificación y en el de justificación del Derecho dado que no siempre son intercambiables entre sí.

\section{EL DEBATE EN TORNO A LA INSTITUCIÓN DE LA LEGÍTIMA}

La institución jurídica de la legítima y en particular el alcance que esta deba tener, ha generado una interesante controversia entre juristas. Así, hay quien sostiene que la legítima debería desaparecer dado que se ha diluido la función que estaba llamada a desempeñar tiempo atrás. Esta posición, ciertamente minoritaria, centra la crítica en la pérdida de eficacia del instituto jurídico, que justificaría su derogación ${ }^{1}$.

La gran mayoría de la dogmática se inclina, sin embargo, por reconocer cierta función a la institución legitimaria, aun cuando existen importantes discrepancias en relación con cuál deba ser su alcance ${ }^{2}$.

De este modo, defensores y detractores coinciden en señalar el impacto que el derecho de legítima tiene en el de propiedad. Pero mientras que para los primeros la pérdida de eficacia del instituto jurídico justificaría su desaparición, que conllevaría, a su vez, una adecuada protección del derecho de propiedad ${ }^{3}$; para los segundos tal pérdida de eficacia es, en todo caso, relativa y, a lo sumo, lo que el instituto jurídico requiere es alguna modificación que permita atemperar ambos derechos ${ }^{4}$. De este modo, las razones que alegan los defensores y detractores de la legítima tienen en común que se basan en algún cálculo de utilidad, o lo que es lo mismo, de eficiencia del Derecho.

No deja de ser curioso que el debate, así planteado, se centre en una cuestión valorativa o, si se prefiere, externa al ordenamiento jurídico, antes que en la descriptiva o interna. La cual es, por otra parte, la que se espera que los juristas aborden en primer lugar.

Ciertamente, la doctrina es unánime a la hora de reconocer la plena vigencia de la institución de la legítima allí donde existe. Y justamente ocurre lo contrario en los ordenamientos jurídicos que no la contemplan o que, como es el caso del español, admiten una variedad de regímenes que transitan de uno a otro extremo. Pero esto no permite avanzar demasiado. A lo sumo, se puede concluir que existe un reconocimiento generalizado de los operadores jurídicos que dota de estabilidad a cada ordenamiento jurídico de referencia, lo cual permite, a su vez, abordar una discusión coherente sobre las razones internas y externas que justifican la existencia o inexistencia de la legítima en cada uno de ellos 5 . Ahora bien, esto exige deslindar adecuadamente unas y otras razones. Es decir, analizar en primer lugar si existen razones internas que justifiquen la existencia o inexistencia de la legítima y, con independencia de cuál sea la respuesta,

\footnotetext{
1 Calatayud (1995), Valladares (2004) y Magariños (2005).

DíEZ-PiCAZo y Gullón (2006) y Delgado (2006).

VALladares (2004), Magariños (2005) y Cobas (2006).

4 LÓPEZ (2002), PARRA (2009) y DELGADO (2011) y (2012).

5 Una esmerada exposición de las diferentes regulaciones de la legítima en el derecho comparado se encuentra en ALCOY (2007) y PARRA (2009).
} 
esgrimir después las de utilidad ${ }^{6}$. De no hacerlo así, el debate jurídico se torna farragoso y tienden a confundirse dos planos diferentes, aunque relacionados, del Derecho.

Pero no adelantemos acontecimientos que no hacen más que entorpecer el hilo argumental. Veamos primero en qué consiste la institución de la legítima y de qué tipo son las razones que se ofrecen a favor y en contra de la misma.

\subsection{La institución de la legítima}

La legítima viene definida en el art. 806 del Código Civil español como

«... la porción de bienes de que el testador no puede disponer por haberla reservado la ley a determinados herederos, llamados por esto herederos forzosos» ${ }^{7}$.

La norma que se extrae de este enunciado es claramente imperativa: la prohibición de disposición $(P h \mathrm{~d})$ del testador de esa porción de bienes de la cual es titular. Así pues, a tenor de lo que dispone el art. 806 del CC, la legítima opera como un límite a la voluntad expresa del causante. O dicho de otro modo, el derecho de los legitimarios queda fuera de la capacidad de decisión del propietario testador ${ }^{8}$. Puede afirmarse en consecuencia que, en tanto que norma imperativa, una de las caras de la legítima resguarda el derecho de los legitimarios, mientras que la otra impone una restricción a la voluntad del causante. En suma, la obligatoriedad de la legítima $(O l)$ lleva aparejada la prohibición de disposición del titular del derecho de propiedad $(\mathrm{Phd}$ ) A continuación examinaré con un poco más de detalle cada una de estas vertientes de la legítima.

\subsubsection{La legítima como derecho de los legitimarios}

En tanto que derecho de los legitimarios $(\mathrm{Ol})$, la legítima protege el interés de los parientes más próximos del causante, generalmente descendientes y ascendientes, y en algunos casos al cónyuge. Las razones que avalan este derecho de los legitimarios son dispares. En algunas ocasiones se afirma que el derecho de legítima garantiza cierta igualdad entre los herederos, a los que el Código Civil denomina forzosos en desafortunada expresión. Otras que el instituto de la legítima asegura cierta función asistencial de la herencia y contribuye con ello a fortalecer la solidaridad intergeneracional ${ }^{9}$.

Sin perjuicio de la inapropiada expresión del Código Civil, que llama a la confusión entre herederos y legitimarios pese a la diferente posición jurídica que ostenta cada uno de ellos ${ }^{10}$; la institución de la legítima parece llamada a cumplir ciertas funciones básicas

\footnotetext{
6 Como afirma Vilajosana, la importancia del análisis conceptual radica en «ofrecer una concepción de nuestra red conceptual en un determinado campo que pueda explicar nuestras intuiciones conceptuales»; VILAJOSANA (2007).

7 Cfr. art. 806 del Código Civil.

8 La jurisprudencia no ofrece ninguna duda en relación con este extremo. Véanse al respecto SSTS de 5 de octubre de 1991, 6 de abril de 1998 y 9 de julio de 2002.

9 SChÖPflin (2006), DE WAal (2007) y LAMARCa (2014).

10 Ciertamente el heredero puede serlo por voluntad del causante o por previsión legal, mientras que el legitimario tan solo obedece a esta última. Por lo demás tanto herederos como legitimarios pueden renunciar a su derecho, por lo que el calificativo de forzoso tan solo opera contra la voluntad del causante.
} 
del Derecho. Proporciona seguridad jurídica a los parientes más próximos del causante dado que asegura sus expectativas frente a los actos de disposición de aquel, bien sean inter vivos o de última voluntad. Soluciona también un problema de coordinación entre los herederos del causante y entre este y aquellos. El derecho de los legitimarios condiciona ciertamente los actos de disposición del causante y, de este modo, permite acomodar las decisiones de uno y las expectativas de los otros ${ }^{11}$. A ello habría que añadir que este instituto jurídico vendría a evitar un problema de interacción estratégica entre los herederos de tal manera que evitaría la competencia desleal entre ellos ${ }^{12}$. La función de justicia social, en fin, porque si es discutible que una obligación jurídica como la que impone la institución de la legítima contribuya a fortalecer una razón moral como es la solidaridad intergeneracional, lo cierto es que garantiza al menos el derecho de los parientes más próximos a una porción de los bienes del causante ${ }^{13}$. Cuestión diferente es, si este es el concepto de solidaridad intergeneracional que debe proteger el Derecho.

Sea como fuere, lo cierto es que una vez examinada esta cara de la legítima parece innegable que posee cierta utilidad.

\subsubsection{Y como restricción de la voluntad del causante}

La cruz de la moneda es la restricción que la legítima impone a la voluntad del causante $(P h d)$. El grueso de la controversia radica aquí en la cuestionada utilidad de un instituto jurídico que en la actualidad difícilmente cumple las funciones que estuvo llamado a desempeñar. Con el fin de liberar o al menos disminuir el peso de esta carga legal a la que queda sujeto el testador se han hecho varias propuestas interesantes. También entre ellas se encuentran razones variadas que justifican la revisión de la legítima. Algunas se refieren a la conveniente adaptación del ordenamiento jurídico a un mundo cada vez más globalizado en el que la tendencia parece ser la erradicación o en todo caso disminución notable de las legítimas ${ }^{14}$. Otras señalan el progresivo envejecimiento de nuestras sociedades, con lo que pierde peso la función asistencial y de sustento que la legítima cumplió en otras épocas. Sin que falten las que señalan que el instituto de la legítima es actualmente un obstáculo para el desarrollo del sector empresarial ${ }^{15}$. Últimamente van cobrando importancia también las propuestas que se refieren a la necesidad de relajar las causas de privación de la legítima ${ }^{16}$. Todas estas razones hacen hincapié en la perdida de utilidad y, en definitiva, la ineficiencia de un instituto jurídico que ha devenido arcaico y que genera, además, problemas jurídicos relevantes como pueden ser los de determinación de la ley aplicable a los actos de última voluntad o declaraciones de nulidad ${ }^{17}$.

Como hemos visto hasta aquí, tanto las razones a favor como en contra de la legítima hacen referencia a su utilidad, es decir a lo que cabría denominar la justificación

\footnotetext{
11 Busto (2015).

12 Cainismo entre parientes, lo denomina LAMARCA (2014).

13 López (1994), CARrasco (2003), DE WAal (2007) y LAMARCa (2014).

14 Alcoy (2007) y FerRer (2011).

15 MAgariños (2005) y SÁEZ-SANTURTUN (2008).

16 Arroyo y Farnós (2015).

17 Álvarez (2011).
} 
externa del instituto jurídico. Ninguna de ellas atiende sin embargo a la justificación interna, que quizá resulte apropiado considerar por si arrojase alguna luz sobre el problema.

\section{EL ENCAJE CONSTITUCIONAL DE LA LEGÍTIMA}

En el caso del ordenamiento jurídico español, la institución de la legítima ha sobrevivido sin variación sustancial a la reforma constitucional. La doctrina se muestra por lo general unánime a la hora de reconocer el encaje de este instituto en el ordenamiento jurídico constitucional, sea cual sea la caracterización que haga de ella en el régimen general o en los diferentes derechos civiles regionales. Es decir, se asume que el reconocimiento expreso del derecho de herencia en el art. 33.1 de la Constitución española otorga carta de validez constitucional a la legítima. Nótese que aquí se encuentra la clave de la genuina controversia jurídica. Si el juicio de validez o justificación interna es positivo, el resto de consideraciones en relación con su mayor o menor utilidad tienen sentido, pero en caso contrario deben ser descartadas. No deja de ser curioso, sin embargo, que esta cuestión sea la que menos interés despierta entre los juristas ${ }^{18}$.

Como el art. 33.1 CE reconoce conjuntamente «el derecho a la propiedad privada y a la herencia», se colige que la protección de la primera conlleva el respeto de la segunda dado que se garantiza con ello una mínima vinculación familiar del patrimonio del causante. Incluso las escasas voces críticas al respecto coinciden en señalar que es posible compatibilizar la institución de la legítima, la vinculación de una parte del patrimonio del causante a los parientes más próximos, con la capacidad de decisión del causante sobre su patrimonio para después de su muerte ${ }^{19}$.

Seguramente debido a esta aceptación unánime de la legítima no se ha presentado la ocasión de que el Tribunal Constitucional español se pronuncie sobre esta cuestión. Sí lo ha hecho, sin embargo, el alemán. Este último, en Sentencia de 19 de abril de 2005, afirma sin ambages que si bien la libertad de disposición del causante es el corolario del derecho de propiedad y que no existe en consecuencia mandato constitucional alguno por el que el causante deba conceder un trato igual a sus descendientes, el mismo derecho de propiedad merece una participación mínima de los hijos en la herencia que se alcanza mediante la legítima. Las razones que ofrece el alto tribunal alemán son parecidas, sino idénticas, a las mencionadas anteriormente: la protección constitucional de las relaciones entre padres e hijos, la vinculación del patrimonio familiar y la solidaridad intergeneracional ${ }^{20}$. En definitiva, que el Derecho existente es también el que debe ser.

\footnotetext{
18 Como excepción, es encomiable el esfuerzo exegético que en este sentido realiza LópEz (1994).

19 LÓPEZ (2000: 279) y DELGADO (2011) y (2012).

20 VAquer (2007), Pintens \& Seyns (2009) y Delgado (2012).
} 


\section{EL PROBLEMA SUBYACENTE. LA TITULARIDAD DE LOS DERECHOS}

El problema que subyace al desacuerdo entre juristas, tal y como ha sido expuesto hasta aquí, parece radicar en una divergencia profunda a la hora de interpretar el art. 33.1 CE, que como hemos visto reconoce el derecho de propiedad y el de herencia por igual ${ }^{21}$. Ciertamente, con independencia de que colisionen entre sí, el contenido de ambos derechos viene delimitado por su función social (art. 33.2 CE). Así, el derecho de propiedad privada queda supeditado a la utilidad pública o interés social (art. 33.3 CE), al estado de necesidad de ciertos parientes, como ocurre con la obligación de alimentos (art. 143 CC). Por otra parte, los diversos impuestos que gravan la propiedad afectan sin duda al disfrute pleno de la misma con la finalidad de distribuir la riqueza. Por su parte, el derecho de herencia, además de por algunas de las anteriores, también se encuentra limitado individualmente por cuestiones de indignidad (art. 756 CC), maltrato o injurias (art. 853 CC). Así pues, dada la generalidad con la que el art. 33.1 CE enuncia ambos derechos, parece que es aquí donde se encuentra el problema antes que la solución. Es decir, dado que ambos derechos son enunciados de forma genérica o, si se prefiere, principialista, la cuestión que hay que resolver es cuál de ellos tiene prioridad cuando colisionan entre sí, como ocurre claramente en el caso de la legítima ${ }^{22}$.

Pero esta forma de plantear la cuestión no es del todo neutral. En realidad no denota una divergencia sino todo lo contrario. Nótese que con ello se asume que hay una única lectura del art. 33.1, a saber, la de la diferente titularidad del derecho de herencia y el de propiedad. Esta tesis que denominaré tesis de la disyunción de la titularidad (TDT), podría enunciarse del siguiente modo:

TDT: «se reconoce el derecho de disposición del propietario de los bienes excepto sobre una porción de ellos reservada a sus parientes más próximos».

Esta parece ser una manera adecuada de cohonestar ambos derechos. Ciertamente, de esta forma el ordenamiento jurídico protege el derecho de propiedad y el de herencia a la vez que deja en manos del legislador la cuantía máxima que puede detraerse del primero y la mínima con la que se dota al segundo. El ordenamiento jurídico adoptaría de este modo una posición de garante con respecto a la protección de los intereses del propietario y de sus herederos. Del primero porque no le impide disponer libremente de la mayor parte de sus bienes al tiempo que resguarda otra parte con la finalidad de dar continuidad al patrimonio familiar y proteger las expectativas de los segundos ${ }^{23}$. De acuerdo con esta lectura la garantía institucional de la que goza la herencia abarcaría también el derecho de legítima.

Sin embargo, también cabe otra lectura del art. 33.1 CE. De acuerdo con esta segunda interpretación, podría entenderse que el derecho de herencia no es sino el

21 Llama la atención sobre este problema interpretativo LÓPEZ al afirmar que «el verbo "reconocer" que se emplea en el art. 33.1 del texto constitucional, carece de preciso sentido»; LÓPEz (1994: 50).

${ }_{22}$ Lo cual conduce a un farragoso proceso ponderativo en el que se entremezclan, a decir de LÓPEZ, elementos valorativos, sociológicos, funcionales, etc.; LÓPEZ (1994: 51 y ss.).

${ }_{23}$ Que vendría justificado en virtud del denominado «principio de vinculación familiar del patrimonio a la hora de la sucesión mortis causa»; LóPEZ (1994: 54). 
corolario del carácter temporalmente ilimitado de la propiedad privada, también después de la muerte de su titular. Esta tesis, que llamaré de la conjunción de la titularidad (TCT), puede enunciarse del siguiente modo:

TCT: «se reconoce la propiedad privada y la disposición a cualquier título por parte de su titular».

De acuerdo con esta lectura alternativa, el ordenamiento jurídico adoptaría de nuevo una posición de garante, pero en este caso del disfrute y libre disposición de la propiedad privada por su titular, también para después de la muerte. Nótese que esta segunda lectura permite garantizar tanto la libertad de disposición del titular de los bienes cuanto el derecho de los herederos a mantener en manos privadas el patrimonio del causante para el caso de que este no haya dispuesto expresamente de él ${ }^{24}$.

Ambas lecturas son ciertamente posibles pero no pueden esgrimirse conjuntamente dado que son incompatibles entre $\mathrm{si}^{25}$. Por de pronto cabe preguntarse qué razones justifican la adopción de esta posición de garante del ordenamiento jurídico en uno y otro caso. Quien se acoja a la primera de ellas (TDT), se verá obligado justificar las razones, paternalistas o de otro tipo, que avalan el derecho de legítima, en tanto que opera contra la voluntad expresa del titular del derecho de propiedad. La segunda lectura (TCT) es, por el contrario, inmune a cualquiera de esas razones. Brevemente, para TCT las únicas razones que importan son internas y se atienen en consecuencia a los criterios que ofrece el propio ordenamiento jurídico.

Conviene evitar la confusión entre ambas tesis dado que puede dar lugar a equívocos importantes. Tal es el caso de lo que ocurre al tomar una parte de TCT para justificar la totalidad de TDT. Así sucede, por ejemplo, cuando el derecho del causante a disponer de sus bienes por título mortis causa pretende usarse como justificación de la situación de potestad o privilegio en la que se encuentran los parientes más próximos en relación con una porción de sus bienes. Nótese que lo que TCT defiende es la conjunción de la titularidad y, en consecuencia, el derecho del titular a disponer de la totalidad de sus bienes por título mortis causa o por cualquier otro. Es decir, el derecho de propiedad es visto desde TCT como un genuino derecho subjetivo en sentido kelseniano, en tanto que provee al titular de una potestad jurídica frente al resto ${ }^{26}$. Este derecho subjetivo sería también el que se transmitiría a los herederos en el caso de que el titular de los bienes no disponga de ellos. Justamente lo contrario es lo que ocurre con TDT dado que al invertir el derecho y su correlativa obligación sitúa a los parientes del causante en una posición de privilegio frente a este, o si se prefiere deja al titular de los bienes en una situación de no derecho ${ }^{27}$.

${ }^{24}$ A esto es a lo que parece referirse LÓPEZ cuando afirma que «la garantía institucional de la herencia lo que expresa de una manera primaria es la preservación de un ámbito de poder del individuo sobre sus bienes, más allá de su muerte, lo que por pura lógica no es otra cosa sino un círculo de disposición de bienes contemplatione mortis. Sin la existencia de este poder individual la garantía quedaría aniquilada», LóPEZ (1994: 50).

${ }^{25}$ LóPEZ realiza un encomiable esfuerzo por compatibilizar ambas tesis pero como el propio autor reconoce este «discurso deviene extraordinariamente resbaladizo», LÓPEZ (1994: 56).

26 KeLSEN (1960: 147).

27 De acuerdo con HOHFELD obligación y no derecho son los correlatos de derecho y privilegio. Cuando se afirma que $\mathrm{X}$ tiene el derecho de propiedad sobre algo se dice con ello que $\mathrm{Y}$ tiene la obligación de respetarla. En el mismo sentido puede afirmarse que $\mathrm{X}$ se encuentra en una posición de privilegio frente a $\mathrm{Y}$, o que $\mathrm{Y}$ está en una situación de no derecho frente a X. HoHFELD (1913: 38-9). 


\section{LOS CUERNOS DEL DILEMA}

Parece pues que nos encontramos ante un dilema interpretativo cuya solución pasa por tomar partido por uno de sus cuernos. De este modo, o bien se da plena protección al derecho de propiedad, como exige TCT; o bien se restringe la posibilidad de disposición de su titular en aras de la protección del patrimonio y los intereses de ciertos parientes del causante sobre él, como requiere TDT.

De acuerdo con el tenor en el que se expresa el art. 33.1 CE, para acogerse a la primera de las soluciones tan solo es necesario aferrarse a la dicción literal del artículo. Dado que el derecho de propiedad y el de herencia vienen unidos por el texto constitucional, no debe separarlos el legislador. Al fin y al cabo, una de las máximas más firmemente arraigadas entre los juristas es in claris no fit interpretatio.

Los críticos parecen ser más escépticos en relación con lo que exige el Derecho. Pero el escepticismo, aunque mayoritario, tiene diferentes grados.

\subsection{El cuerno interpretativo del derecho...}

Para desvirtuar el argumento literal, y en consecuencia el dilema, los defensores de la legítima afirman que dado que no está claro qué exige el art. 33.1 CE, la solución requiere estipular una respuesta, y esta pasa por equilibrar ambos derechos. La institución de la legítima, concluyen de este modo, no solo tiene perfecta cabida dentro del texto constitucional sino que es, además, la forma más coherente de compatibilizar el derecho de propiedad y el de herencia. Cuestión diferente es el alcance que a favor de uno u otro derecho se dé a dicha institución. Este sería, en consecuencia, el problema relevante en el que debe centrarse la discusión jurídica. Pero esta es una estrategia que no está exenta de complicaciones.

La primera y más obvia de las objeciones que cabe hacer a esta forma de presentar las cosas es que debe diferenciarse el proceso de decisión de la decisión como producto. En tanto que producto, la decisión bien puede ser el resultado de una estipulación que, por definición, está vinculada con preferencias, no con razones. Es decir, estipular que una, entre las varias posibles, es la solución de un caso, se debe a que las razones a favor de esta y las restantes soluciones colapsan entre sí y, en consecuencia, la opción por la que se inclina el decisor es aquella que satisface en mayor medida sus preferencias. Pero esto quiere decir que esa opción tiene el mismo peso que la que pueda tomar otro decisor con preferencias diferentes.

Pero que las decisiones estipulativas se basen en preferencias y no en razones no implica que el proceso de decisión jurídica deba atenerse a las preferencias del decisor $^{28}$. Dicho de otro modo, la decisión jurídica puede ser finalmente acorde con las intuiciones del decisor. Pero lo será no por razón de la intuición, sino por la validez

28 Denomino intuitivas a aquellas preferencias basadas en emociones o experiencias personales, como las que expresan López (1994: 53), LACRUZ (2004: 318) o LAMARCA (2014: 252 y 274), carentes, por tanto, de cualquier justificación basada en criterios constructivos. Sobre la debilidad justificativa del intuicionismo y las formas más comunes de perfeccionismo a las que conduce, véase RAWLS (1971: 34-40). 
de las razones que se esgriman en defensa de la intuición. Tales razones, por lo demás, podrán ser jurídicas o de otro tipo y devienen totalmente secundarias en el caso de que el resultado de la decisión sea finalmente una estipulación. Es aquí donde se encuentra la segunda de las objeciones que cabe hacer a TDT.

Como hemos visto la preferencia por TDT tiene que ver con la utilidad de la legítima, la protección de las expectativas de los familiares o la continuidad del patrimonio familiar. Aunque ciertamente dispares, todas ellas omiten cualquier análisis de la titularidad de los derechos de propiedad y herencia. Asumen, en consecuencia, que hay una lectura del art. 33.1 CE, que es sobre la que se sustenta TDT. Es decir, que hay una colisión entre ambos derechos y para deslindarlos tan solo cabe recurrir al ejercicio de ponderación.

\section{2. ... y del revés}

Para analizar el alcance de las razones que avalan la preferencia de TDT quizá sea conveniente plantear la cuestión a la inversa. Es decir, preguntarse si dado que los derechos de propiedad y herencia vienen unidos en el texto constitucional, las razones que permiten restringir uno y otro vienen también definidas en el ordenamiento jurídico. El propio texto constitucional supedita, como vimos, el derecho de propiedad a su función social. Existen, además, otras restricciones como las impuestas a los menores o incapaces, que tienen que ver con medidas paternalistas cuya finalidad es la protección del patrimonio del titular, bien sea por cuestiones de índole temporal o de capacidad intelectual. Hay también restricciones que, como antes dije, están relacionadas con ciertos estados de necesidad. Sin embargo, ninguna de estas razones sirve para justificar la legítima. Ciertamente, la institución de la legítima difícilmente puede relacionarse con el interés nacional, la redistribución de la riqueza, el estado de necesidad de los parientes o la incapacidad para decidir del titular de los bienes ${ }^{29}$. Más bien ocurre todo lo contrario: hay una decisión expresa del testador que, debemos suponer, se ha realizado haciendo uso de sus plenas facultades mentales, dado que de lo contrario lo que debería impugnarse es la validez jurídica del testamento. Y, si esto es así, tan solo cabe concluir que la preferencia por TDT se enroca en una suerte de perfeccionismo jurídico que se desentiende injustificadamente del derecho de propiedad y de la libertad de su titular de disponer de sus bienes ${ }^{30}$.

Pero TDT aun tiene que hacer frente a la objeción más demoledora, a saber, la de basarse en un argumento circular que pide el principio.

$\mathrm{El}$ argumento sobre el que se asienta TDT consta de tres pasos. El primero consiste en suponer que el derecho de propiedad y el de herencia tienen diferente titularidad. El siguiente paso sostiene que cuando ambos derechos colisionan entre sí, como es el caso de la legítima, hay que encontrar algún equilibrio entre el derecho del propietario a disponer de sus bienes y el de ciertos parientes a heredarlos. La conclusión, como es

29 Así pues, las razones en las que se basaba la justificación de TDT (vid. supra 4) desembocan en un paternalismo jurídico injustificado. Sobre la justificación del paternalismo jurídico GARZÓN (1988).

30 Como afirma RAWLS (1971: 325) en relación con el «principio de perfección»: «The requirments of perfection override the strong claims of liberty». 
obvio, es que esta es precisamente la finalidad a la que responde la legítima. Pero esta forma de presentar la cuestión no es del todo correcta.

Nótese que en la primera premisa se presupone la separabilidad de ambos derechos y, en consecuencia, que la garantía institucional de la que gozan el derecho de propiedad y el de herencia se extiende a la legítima; que es precisamente lo que TDT debe probar.

Veamos ahora de qué modo se construye el argumento sobre el que se sostiene TCT. Recuérdese que esta tesis defiende la conjunción de ambos derechos, por lo que en principio queda libre de toda pirueta argumental. Ahora bien, TCT aun tiene que probar las razones que avalan el argumento literal.

Para ello TCT tan solo necesita aferrarse al primero de los recursos interpretativos que contempla el propio ordenamiento jurídico, que no es otro que el de la interpretación literal o gramatical (art. 3.1 CC). Siempre cabe cuestionar la utilidad de este criterio dado que es precisamente el alcance de uno y otro derecho lo que se encuentra en discusión. Pero esta objeción tan solo tiene sentido a partir de algunos presupuestos:

i) que la interpretación literal es plenamente coherente con el ordenamiento jurídico desde el momento en el que este admite regímenes regionales en los que no rige la legítima y por lo tanto está permitida la plena disposición del titular $(P \mathrm{~d})$. Con ello decae en consecuencia el argumento de la extensión de la garantía institucional de la herencia a la legítima ${ }^{31}$.

ii) que, por muy vagos que sean los conceptos de herencia o propiedad, es indiscutible que ambos vienen unidos en el texto constitucional y no parece que sea apreciable en la conjunción algún defecto de vaguedad.

iii) que el resto de criterios interpretativos que señala el art. 3.1 CC, es decir, el sistemático, el histórico y el sociológico tampoco parecen servir de mucha ayuda en el contexto jurídico actual. El sistemático porque una lectura a cobaerentian del ordenamiento jurídico conduce justamente a la conclusión contraria. El histórico porque si bien es cierto que la legítima ha sido tradicionalmente un derecho reconocido a los parientes más próximos, no parece que esta sea una razón suficiente para su mantenimiento en contra del resto de criterios interpretativos que ofrece el ordenamiento jurídico actual. Y el sociológico, en fin, porque como manifiestan las voces críticas de la legítima y demuestran las encuestas disponibles ${ }^{32}$, este instituto jurídico ya no cumple con la función que estaba llamado a desempeñar tiempo atrás.

Llegados a este punto a TCT tan solo le cabe preguntar qué razón avala a la legítima dado que no se apoya en las que justifican el resto de restricciones al derecho de propiedad. Es decir, por qué se mantiene un instituto jurídico que no responde a razones de interés general, de redistribución de la riqueza, de protección del interés del titular de los bienes o, en fin, a algún estado de necesidad. De este modo, la conclusión a la que se llega desde TCT es que la legítima opera en todo caso como un instituto que restringe la voluntad expresa del titular de los bienes sin más razón aparente que la presuposición de que la garantía institucional que se otorga al derecho de herencia

\footnotetext{
31 PARRA (2004: 500).

32 VAquer (2007).
} 
abarca también al de legítima. Es decir, nos encontramos de nuevo en el punto de partida del argumento, que es también el de llegada, o lo que es lo mismo, ante un argumento circular que pide el principio.

\section{APÉNDICE PARA JURISTAS}

Una de las dificultades interpretativas de la práctica jurídica es que en ella convergen dos planos del Derecho, el de identificación y el de justificación, que conviene deslindar adecuadamente a la hora de realizar un análisis riguroso de ella. Es normal que ambos planos tiendan a confundirse en la práctica, no en vano, la jurídica, como cualquier otra práctica social, se asienta sobre ciertas convenciones que son las que, entre otras cosas, nos permiten reconocerla como tal ${ }^{33}$. Pero precisamente por ello conviene no confundir los argumentos que se esgrimen en uno y otro plano ya que no siempre son intercambiables entre sí. Entre otras cosas porque las razones justificativas del Derecho tan solo cobran sentido una vez que se ha superado con éxito la tarea de identificación. Ciertamente esta es la prioritaria para todo jurista y en principio también la más sencilla, siempre que se disponga del arsenal adecuado para interpretar ${ }^{34}$. Ahora bien, aun cuando se muestre cierto escepticismo ante lo que exige el Derecho en cada caso particular, lo más prudente es comenzar por la interpretación más sencilla, o si se prefiere, adoptar el nivel más bajo de interpretación, que es el que impone además el propio ordenamiento jurídico. Y en este sentido la legítima aparece como un elemento extraño o incoherente dentro del ordenamiento jurídico dado que la prohibición de disposición $(\mathrm{Phd}$ ) que se impone al derecho de propiedad carece de más argumento que la muy dudosa extensión de la garantía institucional de la herencia al derecho de ciertos parientes que, paradójicamente, sitúa en una posición de no derecho al titular del derecho de propiedad.

Así pues nos encontramos en este punto ante una inconsistencia entre normas que imputan consecuencias jurídicas incompatibles a la misma condición fáctica, a saber, la titularidad del derecho de propiedad y la prohibición de disposición. Para comprender mejor esta contradicción normativa puede servirnos de ayuda el esquema de inconsistencias lógicas entre normas ideado por Alf Ross ${ }^{35}$. De acuerdo con Ross, la inconsistencia entre normas puede darse de tres maneras diferentes, que denomina total-total, total-parcial y parcial-parcial ${ }^{36}$.

Existe una inconsistencia total-total cuando ninguna de las normas puede ser aplicada sin entrar en conflicto con la otra. Se produce por tanto una incompatibilidad absoluta entre normas. No es este el caso ante el que nos encontramos, se apresurará a decir quien se acoja a TDT, dado que el derecho de propiedad y el de herencia no colisionan totalmente entre sí, como ocurre cuando el titular de los bienes no dispone expresamente de ellos. En este caso, el derecho subjetivo del que goza el titular de la

\footnotetext{
33 Sobre hechos convencionales y regla de reconocimiento VILAJOSANA (2010: 153 y ss.).

34 Aunque ello exiga en ocasiones embarcarse en una tarea hercúlea de interpretación como muestra DWORKIN (1986: 313 y ss.).

35 Agradezco a Josep Maria VILAJOSANA haberme recordado lo pertinencia de aplicar en este punto la distinción entre las inconsistencias normativas posibles.

36 Ross (1958: 124).
} 
propiedad, como vimos anteriormente, pasa por el mero hecho de su fallecimiento a manos de los herederos. La conclusión es correcta, pero el razonamiento no. Aunque es cierto que el derecho de propiedad y el de legítima no son totalmente inconsistentes entre sí, la razón de ello no se encuentra en la ausencia de disposición del causante, dado que a esto afecta al derecho de herencia, no al de legítima. Y en todo caso, no puede haber incompatibilidad entre ambos derechos toda vez que el causante, en esta situación, no expresa su voluntad. La razón de que la legítima y el derecho de herencia no sean absolutamente incompatibles se encuentra en que el propio ordenamiento jurídico permite la plena disposición del titular de los bienes (Pd), como ocurre con algunos derechos civiles. Hay, en consecuencia, un campo de aplicación del derecho de propiedad que no entra en colisión con la legítima.

La inconsistencia total-parcial se produce cuando una de las normas no puede ser aplicada sin entrar en conflicto con la otra, mientras que esta tiene un campo de aplicación adicional en el cual no entra en conflicto con la anterior. Diremos, en este caso, que se produce una inconsistencia entre la norma general y la particular. Esta es el tipo de inconsistencia que interesa aquí. La legítima, en tanto que norma particular e imperativa para el testador, $(\mathrm{Ol})$, entra siempre en conflicto con la voluntad expresa del titular de los bienes $(\mathrm{Phd})$. Es cierto que esto ocurre también con otro tipo de restricciones, pero como antes vimos, todas ellas encuentran su justificación en razones de justicia distributiva, incapacidad temporal o cognitiva del titular o, en fin, estados de necesidad de los parientes. Razones que, como vimos también, no son aplicables a la previsión legal de la legítima.

Por último nos encontraríamos ante la inconsistencia parcial-parcial o mera superposición de normas, que ocurre cuando ambas tienen un campo de aplicación en el que colisionan entre ellas pero disponen además de un campo independiente de aplicación en el que no se produce conflicto. Tampoco este es el tipo de inconsistencia aplicable al caso de la legítima.

Con lo anterior pretendo decir que una vez superado el proceso de identificación de lo que requiere el Derecho podrán alegarse razones de peso a favor o en contra del resultado que arroje. Pero en todo caso tales razones operan como instancia crítica del Derecho existente al sustentarse en criterios valorativos adicionales (morales, políticos o económicos) a partir de los que se justificará la decisión de su permanencia o derogación. Pero como es obvio, valorar el mérito o demérito del Derecho es algo que tan solo se puede realizar después de haberlo identificado ${ }^{37}$.

\section{CONCLUSIÓN}

En el presente artículo he pasado revista al debate generado entre la doctrina iusprivatista en relación con la institución de la legítima. Para ello, he tratado de reconstruir, en el apartado segundo, los argumentos ofrecidos a favor y en contra de la misma. Todos ellos se sustentan, como se ha visto, en la mayor o menor eficacia que tiene la

37 En palabras de AUSTIN «la existencia del Derecho es una cosa; su mérito o demérito otra»; AUSTIN (1995: 157). 
legítima en la actualidad. Es decir, en un cálculo de utilidad o si se prefiere de eficiencia del Derecho. Así las cosas, el debate se plantea a partir de la asunción de que este instituto jurídico es plenamente coherente con la estructura del ordenamiento jurídico vigente $\mathrm{y}$, a partir de aquí, se ofrecen razones a favor su permanencia o modificación. En algunos casos, ciertamente los menos, se esgrimen también razones que avalan su derogación .

A mi modo de ver, esta forma de presentar la cuestión no es del todo correcta por dos razones. La primera se refiere a que con ello no se hace sino preterir un análisis que debe ser prioritario en el ámbito jurídico, cual es el de la identificación de aquello que requiere el Derecho. La segunda hace alusión a la objeción de circularidad del argumento en torno al cual gira el debate planteado de este modo. Ello permite omitir el análisis de coherencia interna del ordenamiento jurídico, el cual, como vimos, está estrechamente relacionado con lo anterior.

Para arrojar algo de luz sobre lo primero examiné en el tercer apartado la titularidad de los derechos de propiedad y de herencia que vienen conjuntamente enunciados en el art. 33.1 de la Constitución española. De acuerdo con la dicción literal de este artículo afirmé que se podían realizar dos lecturas completamente dispares entre sí. La primera, que denominé tesis de la disyunción de la titularidad (TDT), que asume acríticamente la doctrina mayoritaria, afirma que uno y otro derecho tienen distinta titularidad, sin ofrecer más razón que la garantía institucional que les otorga el texto constitucional. La segunda, que llamé tesis de la conjunción de la titularidad (TCT), sostiene por el contrario que hay argumentos para defender que el derecho de propiedad y el de herencia tienen idéntica titularidad. Las razones que avalan esta tesis se encuentran, como dije también, en que el propio tenor literal del texto constitucional permite afirmar que el derecho de propiedad se encuentra configurado como un genuino derecho subjetivo y, en tanto que tal, no admite más causas de restricción que las que vienen justificadas por los fines a los que atiende el ordenamiento jurídico.

En relación con la segunda de las razones, la que se refiere a la objeción de circularidad, afirmé que para que esté justificado apartarse de la interpretación literal, el argumento alternativo debe construirse sobre premisas más firmes que las que presuponen lo que se quiere probar, a saber, que ambos derechos colisionan entre sí porque tienen diferente titularidad. Para mostrar la debilidad de este argumento propuse, por último, analizar la cuestión desde la perspectiva inversa. Esto me permitió poner de manifiesto i) que la inexistencia de la legítima es plenamente coherente con nuestro ordenamiento jurídico y en consecuencia resulta inviable el argumento de la extensión de la garantía institucional, y ii) que las razones que se ofrecen a favor de la legítima se apartan en todo caso de las que el propio ordenamiento señala como justificativas del resto de restricciones que se imponen al titular del derecho de propiedad.

Finalmente, a partir de la tipología de incompatibilidades lógicas de Ross, identifiqué el tipo de inconsistencia que introduce la legítima en el ordenamiento jurídico. Con ello pretendo poner de manifiesto que si bien en la práctica jurídica aparecen generalmente entremezclados el plano identificativo y el justificativo del Derecho, conviene diferenciarlos adecuadamente cuando se pretende realizar un análisis escrupuloso de esta práctica con el fin de señalar los errores en los que recae y proponer vías de solución constructivas. 


\section{BIBLIOGRAFIA}

Alcoy, A., 2007: «Reflexiones sobre una eventual reforma de la legítima», en InDret. Revista para el análisis del Derecho, 3, bttp://www.indret.com/pdf/457_es.pdf.

ÁlvarEZ, S., 2011: «Las legítimas en el Reglamento sobre sucesiones y testamentos», en Anuario Español de Derecho Internacional Privado, XI, 369-406.

ARroYo, E., y FARNÓs, E., 2015: «Entre el testador abandonado y el legitimario desheredado ¿a quién prefieren los tribunales?», en InDret. Revista para el análisis del Derecho, http://www. indret.com/pdf/1132_es.pdf.

Austin, J. [1832], 1995: The Province of Jurisprudence determined, Cambridge: Cambridge University Press.

Busto, J. M., 2015: «Legítimas y reservas», en BerCovitz, R., Manual de Derecho Civil. Sucesiones, Madrid: Bercal, 3. ${ }^{a}$ ed., 207-248.

Calatayud SierRA, A., 1995: «Consideraciones acerca de la libertad de testar», Academia Sevillana del Notariado IX.

Carrasco Perera, A., 2003, «Acoso y derribo de la legítima hereditaria». Actualidad Jurídica Aranzadi, 580.

Cobas Cobiella, M. ${ }^{a}$ E., 2006: «Hacia un nuevo enfoque de las legítimas», Revista de Derecho Patrimonial, núm. 17.

DeLGADO, J., 2006: «Una propuesta de política legislativa en Derecho de sucesiones por causa de muerte. Segunda parte: objetivos de una reforma del Derecho de sucesiones. Presente y futuro», XII Jornadas de la Asociación de Profesores de Derecho civil, Murcia: Servicio de Publicaciones de la Universidad de Murcia.

- 2011: «El fundamento constitucional de la facultad de disponer para después de la muerte», en Diario La Ley, núm. 7675.

- 2012: «Autonomía privada y derecho de sucesiones», en Lorenzo PRATS AlBENTOSA (coord.), Autonomia de la voluntad en el derecho privado: Estudios en conmemoración del 150 aniversario de la Ley del Notariado, vol. 1 (Derecho de la persona, familia y sucesiones), 513-640.

De WaAl, M. J., 2007: «A Comparative Overview», en Reinhard ZimmermanN, Exploring the Law of Succession, Edinburgh: Edinburgh University Press, 1-26.

DíEz-Picazo, L., y Gullón, A., 2006: Sistema de Derecho civil, IV, 10 ed., Madrid.

Dworkin, R., 1986: Law's Empire, Cambridge, Massachusetts: The Belknap Press of Harvard University Press.

FERRER RibA, J., 2011: La successió per causa de mort: llibertat de disposar i interessos familiars, en C. E. Florensa i TOMÀs (dir.) y J. M. Fontanellas Morell (coord.), La codificación del derecho civil de Cataluña. Estudios con ocasión del cincuentenario de la Compilación. Madrid, Barcelona, Buenos Aires: Marcial Pons, 337-362.

GARZÓN, E., 1988: «¿Es éticamente justificable el paternalismo jurídico?», Doxa, 5, 155-73.

HoHFELD, W. N., 1923: Some fundamental legal conceptions as applied in judicial reasoning and other legal essays. New Haven: Yale University Press.

KELSEN, H., 1960: Teoría pura del Derecho, trad. esp., por la que se cita, de Reine Rechtslebre, zweite, vollständing neu bearbeitete und erweiterte Auflage, a cargo de VERNENGO, R., 11. ${ }^{a}$ ed., México: Porrúa, 2000.

Lacruz Berdejo, J. L., 2004: Elementos de Derecho civil V, Sucesiones, Madrid: Dykinson.

LamarcA, A., 2014: We Are Not Born Alone and We Do Not Die Alone: Protecting Intergenerational Solidarity and Refraining Cain-ism Through Forced Heirship. Oñati Socio-legal Series [online], 4 (2), 264-282. Available from, http://ssrn.com/abstract=243105. 
LóPEZ, A., 1994: «La garantía institucional de la herencia», en Derecho Privado y Constitución, 3 , 29-62.

— 2002: «El derecho a la propiedad privada y a la herencia. Función y límites», en J. L. Moreneo Pérez, Cristóbal Molina Navarrete y M. N. Moreno Vida (dir.), Comentario a la constitución socio-económica de España, Granada.

Magarinos, V., 2005: «La libertad de testar», Revista de Derecho Privado, septiembre/octubre.

PARRA, M. A., 2009: «Legítimas, libertad de testar y transmisión de un patrimonio», en Anuario de la Facultade de Dereito da Universidade da Coruña, 13, 481-554.

PInTENS, W., y SEYnS, S., 2009: «Perspective 5. Comparative Law - Germany. Compulsory Portion and Solidarity Between Generations in German Law», en C. Castelein, R. Foqué y A. VERBEKE (eds.), Imperative Inheritance Law in a Late-Modern Society. Five Perspectives. Antwerp, Oxford, Portland: Intersentia, 167-188.

RAWls, J., 1971: A Theory of Justice, Cambridge, Massachusetts, London: The Belknap Press of Harvard University Press, 2005.

Ross, A., 1958: El Derecho y la justicia. Traducción al español por la que se cita de On Law and Justice, a cargo de G. CARRIÓ, Buenos Aires: EUDEBA, 1994, 5. . ed.

SAEZ-SANTURTUN, J., «Intervención notarial en la estructuración de las pequeñas y medianas empresas», Revista Juridica del Notariado, núm. IX, extraordinario.

SCHÖPflin, M., 2006: «Economic Aspects of the Right to a Compulsory Portion in the (French and German) Law of Succession», German Working Papers in Law and Economics, 2006, paper 34, http://www.bepress.com/gwp, 2008.

VALLADARES, E., 2004: «Por una reforma del sistema sucesorio del Código civil», en Libro Homenaje al profesor M. Albaladejo, t. II, Murcia.

Vilajosana, J. M., 2010: El derecho en acción. La dimensión social de las normas jurídicas. Madrid, Barcelona: Marcial Pons.

- 2014: Identificación y justificación del Derecho. Madrid, Barcelona: Marcial Pons. 